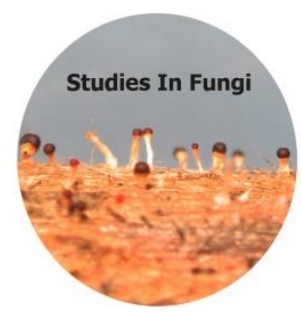

Studies in Fungi 2 (1): 235-245 (2017) www.studiesinfungi.org ISSN 2465-4973

\title{
Article
}

Doi 10.5943/sif/ 2/1/27

Copyright $\odot$ Mushroom Research Foundation

\section{Multi-gene phylogeny of Jattaea bruguierae, a novel asexual morph from Bruguiera cylindrica}

\section{Dayarathne $\mathrm{MC}^{1,2}$, Abeywickrama $\mathbf{P}^{1,2,3}$, Jones EBG ${ }^{4}$, Bhat $\mathrm{DJ}^{5,6}$, Chomnunti $\mathbf{P}^{1,2}$ and Hyde KD ${ }^{2,3,4}$}

${ }^{1}$ Center of Excellence in Fungal Research, Mae Fah Luang University, Chiang Rai 57100, Thailand.

${ }^{2}$ School of Science, Mae Fah Luang University, Chiang Rai57100, Thailand.

${ }^{3}$ Institute of Plant and Environment Protection, Beijing Academy of Agriculture and Forestry Sciences.

${ }^{4}$ Department of Botany and Microbiology, King Saudi University, Riyadh, Saudi Arabia.

${ }^{5}$ No. 128/1-J, Azad Housing Society, Curca, P.O. Goa Velha 403108, India.

${ }^{6}$ Formerly, Department of Botany, Goa University, Goa 403 206, India.

Dayarathne MC, Abeywickrama P, Jones EBG, Bhat DJ, Chomnunti P, Hyde KD 2017 - Multigene phylogeny of Jattaea bruguierae, a novel asexual morph from Bruguiera cylindrica. Studies in Fungi 2(1), 235-245, Doi 10.5943/sif/2/1/27

\begin{abstract}
During our survey on marine-based ascomycetes of southern Thailand, fallen mangrove twigs were collected from the intertidal zones. Those specimens yielded a novel asexual morph of Jattaea (Calosphaeriaceae, Calosphaeriales), Jattaea bruguierae, which is confirmed as a new species by morphological characteristics such as nature and measurements of conidia and conidiophores, as well as a multigene analysis based on combined LSU, SSU, ITS and $\beta$-tubulin sequence data. Jattaea species are abundantly found from wood in terrestrial environments, while the asexual morphs are mostly reported from axenic cultures. Jattaea bruguierae is the first documentation of an asexual morph species from marine- habitats.
\end{abstract}

Key words - marine fungi - morphology - phylogeny - taxonomy

\section{Introduction}

Berlese (1900) introduced Jattaea Berl. and Wegelina Berl. as morphologically similar genera with hyaline, allantoid, one-celled ascospores and clavate asci. They can be distinguished primarily by characters of perithecia and length of the ostiolar neck; papillate to short-beaked in Jattaea vs. cylindrical elongate necks in Wegelina. Jattaea algeriensis Berl. was designated as a respective lectotype by Clements \& Shear (1931). Later, the generic name Jattaea was accepted, with Wegelina as its synonym, to include species with hyaline, allantoid to suballantoid ascospores in clavate, stipitate asci without an apical annulus borne on individual cells on ascogenous hyphae and phialophora-like asexual morphs produced in axenic culture (Réblová 2011). Jattaea species occur usually solitarily, scattered or in small irregular to valsoid groups on wood beneath the periderm, around old fungal stromata or margins of the peeled bark or are rarely immersed in decaying wood. Some species, however, have ascomata arranged in 1-2 vertical levels and in larger groups similar to Calosphaeria Tul. \& C. Tul. The asci in Jattaea are oblong-clavate to clavate and short- to long-stipitate. Multigene analyses by Réblová (2011) also confirmed that septation of ascospores, a diagnostic feature used to separate calosphaeria-like fungi into the genus 
Phragmocalosphaeria Petr., does not appear to be relevant in distinguishing genera in the Calosphaeriales M.E. Barr. Therefore, Phragmocalosphaeria Petr. is also synonymized under Jattaea and hence, it comprises both one-celled and septate ascospores. The genus Jattaea was recently revised using five genes and 17 species are accepted (Réblová et al. 2015).

Asexual morphs of Jattaea are morphologically seen as dematiaceous phialidic hyphomycetes and are referred to as phialophora-like (Damm et al. 2008). They are characterized by semi-macronematous, hyaline, subhyaline to pale yellow-brown conidiophores often reduced to conidiogenous cells such as phialides or adelo-phialides, i.e. single conidiogenous cells without a basal septum. Phialides are hyaline, subhyaline or pale brown, sometimes pigmented in the apical region just below the collarette; they are short-ampulliform to elongate-ampulliform to cylindrical, tapering, with a more or less conspicuous funnel-shaped collarette (Réblová et al. 2015).

The objective of this study is to introduce a novel, marine-based, asexual morph, Jattaea bruguierae from Bruguiera cylindrica (L.) from southern Thailand. Micro-morphology and maximum parsimony, maximum likelihood and Bayesian analyses of combined LSU, SSU, ITS and $\beta$-tubulin sequence data confirmed the phylogenetic placement of this novel species within the family Calosphaeriaceae.

\section{Materials and methods}

\section{Sample collection, specimen examination and isolation}

Fallen, decaying twigs of Bruguiera cylindrica were collected in a mangrove area at Ranong Mangrove Research Center, Mu 4 Tombol Ngao, Amphoe Maung, Ranong Province, Thailand (GPS: $9^{\circ} 43^{\prime}$ to $9^{\circ} 57^{\prime} \mathrm{N}$; $98^{\circ} 29^{\prime}$ to $98^{\circ} 39^{\prime} \mathrm{E}$ ). Twigs were placed in Zip-lock plastic bags and incubated at room temperature in the laboratory. Axenic strains were established from single conidia as described in Chomnunti et al. (2014) with half-strength sea water potato dextrose agar (PDA) (Atlas 2006). Germinating conidia were transferred, under a Motic SMZ 168 Stereo Zoom microscope, to half strength sea water malt extract agar (MEA, $2 \%$ malt extract, Oxoid Ltd., England; $1.5 \%$ agar, Difco, USA) and potato dextrose agar (PDA; $39 \mathrm{~g} / \mathrm{L}$ distilled water and distilled sea water, Difco potato dextrose) for extraction of DNA, determination of growth rates and observation of cultural characteristics. Vegetative hyphae, conidiophores and conidia produced in half strength sea water MEA were observed after six weeks of incubation at $25{ }^{\circ} \mathrm{C}$. Digital images of fruiting structures were captured with a Canon 450D digital camera fitted to a Nikon ECLIPSE $80 \mathrm{i}$ compound microscope. Squash mount preparations were prepared to determine micromorphology. Measurements of morphological structures were taken using the Tarosoft (R) Image Frame Work program and images used for figures processed with Adobe Photoshop CS3 Extended v. 10.0 (Adobe ${ }^{\circledR}$, San Jose, CA). Living cultures are deposited at the Culture Collection of Mae Fah Luang University (MFLUCC) and Thailand Bio Resource Research Center (TBRC). Measurements were taken with the Tarosoft (R) Image Frame Work and Adobe Photoshop CS3 Extended version 10.0 software was used to prepare the photo plates. The herbarium specimen of the new species along with a dry culture comprising conidial structures is deposited in the Mae Fah Luang University Herbarium (MFLU). Faces of fungi and Index Fungorum numbers were registered according to Jayasiri et al. (2015) and Index Fungorum (2017).

\section{DNA extraction, PCR amplification and sequencing}

The Biospin Fungus Genomic DNA Extraction Kit (BioFlux®, China), (Hangzhou, P. R. China) was used to extract DNA from fungal cultures grown on MEA for 14 days at $25{ }^{\circ} \mathrm{C}$ following manufacturer's instructions. Extracted genomic DNA was amplified by using PCR technique with the following ingredients: each amplification reaction contained $0.125 \mu \mathrm{L}$ of 5 units/ $\mu \mathrm{L}$ Ex-Taq DNA polymerase (TaKaRa), $2.5 \mu \mathrm{L}$ of $10 \times$ PCR buffer, $2 \mu \mathrm{L}$ of $2 \mathrm{mM} \mathrm{MgCl} 2$, $2.5 \mu \mathrm{L}$ of $2 \mathrm{mMdNTPs}, 1 \mu \mathrm{L}$ of $0.2-1.0 \mu \mathrm{M}$ primer, $<500 \mathrm{ng}$ DNA template and was adjusted with double-distilled water to a total volume of $25 \mathrm{~mL}$. Temperature profiles and primers used to amplify LSU, SSU, ITS and $\beta$-tubulin gene regions are listed in table 1 . The PCR products were 
observed on $1 \%$ agarose electrophoresis gels stained with Ethidium bromide. Purification and sequencing of PCR products were carried using the above-mentioned PCR primers at Sun biotech company (Beijing, China), for purification and direct sequencing with the same primers. Returned sequences were checked for ambiguity, assembled and deposited in GenBank.

Table 1 Genes/loci used in the study with respective PCR primers and protocols

\begin{tabular}{|c|c|c|c|c|c|c|c|c|c|c|}
\hline \multirow[t]{2}{*}{ Gene/loci } & \multicolumn{2}{|l|}{ Primer } & \multicolumn{3}{|c|}{ PCR protocol } & \multirow[b]{2}{*}{ Anneal. } & \multirow[b]{2}{*}{ Extens. } & & \multirow[b]{2}{*}{ Final ex. } & \multirow[t]{2}{*}{ Reference } \\
\hline & Fd & Rd & $\begin{array}{l}\text { Initial } \\
\text { denatu. }\end{array}$ & Denatu. & & & & & & \\
\hline $\begin{array}{l}\text { ITS } \\
\text { LSU }\end{array}$ & $\begin{array}{l}\text { ITS4 } \\
\text { LR0R }\end{array}$ & $\begin{array}{l}\text { ITS5 } \\
\text { LR5 }\end{array}$ & $94^{\circ} \mathrm{C}, 4 \mathrm{~min}$ & $94^{\circ} \mathrm{C}, 45$ & $\mathrm{sec}$ & $\begin{array}{l}56^{\circ} \mathrm{C}, \quad 45 \\
\mathrm{sec}\end{array}$ & $\begin{array}{l}72^{\circ} \mathrm{C}, \\
\min \end{array}$ & 1 & $\begin{array}{l}72^{\circ} \mathrm{C}, \quad 10 \\
\min \end{array}$ & $\begin{array}{l}\text { White et al. } \\
(1990) \text {, }\end{array}$ \\
\hline SSU & NS1 & NS4 & 1 cycle & 35 cycles & & & & & 1 cycle & $\begin{array}{l}\text { Rehner \& } \\
\text { Samuels } \\
\text { (1994), \& } \\
\text { Vilgalys \& } \\
\text { Hester (1990). }\end{array}$ \\
\hline $\begin{array}{l}\beta- \\
\text { tubulin }\end{array}$ & $\mathrm{Bt} 2 \mathrm{a}$ & $\mathrm{Bt} 2 \mathrm{~b}$ & $94^{\circ} \mathrm{C}, 3 \mathrm{~min}$ & $\begin{array}{l}94^{\circ} \mathrm{C} \\
30 \mathrm{sec}\end{array}$ & $\begin{array}{l}56^{\circ} \mathrm{C}, \\
\sec \end{array}$ & $72^{\circ} \mathrm{C}$ & $1 \mathrm{~min}$ & & $\begin{array}{l}72^{\circ} \mathrm{C}, \quad 10 \\
\min \end{array}$ & $\begin{array}{l}\text { Glass \& } \\
\text { Donaldson } \\
\text { (1995). }\end{array}$ \\
\hline
\end{tabular}

\section{Phylogenetic analysis}

ITS, LSU, SSU and $\beta$-tubulin sequence data was compared by BLAST searches in the GenBank database at the National Centre for Biotechnology Information (NCBI) and sequences were analyzed with other sequences of the family Calosphaeriaceae following Réblová et al. (2015). Sequence data were aligned by MAFFT v. $6.864 \mathrm{~b}$ (http://mafft.cbrc.jp/alignment/server/index.html), and combined using Bioedit 7 (Hall 1999) and MEGA7 (Tamura et al. 2011) and refined visually. Phylogenetic analysis consisted of three methods: Maximum likelihood analysis (ML) was performed by RAxMl GUI v. 1.3 (Silvestro \& Michalak 2012, Stamatakis 2014). The search strategy was set to rapid bootstrapping and the analysis was carried out with 1000 replicates using the GTRGAMMAI model of nucleotide substitution, which was the best model predicted for the combined ITS, LSU, SSU and $\beta$-tubulin data set by MrModeltest v. 2.3.

Bayesian analysis was performed using MrBayes v. 3.0b4 (Ronquist \& Huelsenbeck 2003). Nucleotide substitution models were determined with MrModeltest v. 2.2 (Nylander 2004). A dirichlet state frequency was predicted for all four data partitions and GTR $+\mathrm{I}+\mathrm{G}$ was the best model. The heating parameter was set to 0.2 and trees were saved every 1000 generations (Ronquist et al. 2012). Posterior probabilities (PP) (Rannala et al. 1998, Zhaxybayeva \& Gogarten 2002) were defined by Bayesian Markov Chain Monte Carlo (BMCMC) sampling method in MrBayes v. 3.0b4 (Huelsenbeck \& Ronquist 2001). Six simultaneous Markovchains were run for 500000 generations and trees were sampled every 100th generation resulting in 10000 total trees. 8000 trees were used for calculating posterior probabilities (PP) in the majority rule consensus tree, after discarding the first 1000 trees representing the burn-in phase $(20 \%)$ of the analysis.

Parsimony analysis was performed to obtain the most parsimonious tree. Trees were inferred using the heuristic search option with 1000 random sequence additions. Maxtrees were setup to 1000 and branches of zero length were collapsed and all multiple parsimonious trees were saved. Descriptive tree statistics for parsimony (Tree Length [TL], Consistency Index [CI], Retention Index [RI], Relative Consistency Index [RC] and Homoplasy Index [HI]) were calculated for trees generated under different optimality criteria. Kishino-Hasegawa tests (KHT) (Kishino \& Hasegawa 1989) were performed in order to determine whether trees were significantly different. Maximum likelihood analysis was performed using RAxML GUI v. 1.3 (Silvestro \& Michalak 2012). General time reversible model (GTR) using proportion of invariable sites was applied with a discrete gamma distribution and four rate classes. The best scoring tree was selected with a final 
Table 2 GenBank and culture collection accession numbers of isolates included in this study. Sequences generated in this study are in blue.

\begin{tabular}{|c|c|c|c|c|c|}
\hline \multirow[t]{2}{*}{ Taxon } & \multirow[t]{2}{*}{ Source } & \multicolumn{4}{|c|}{ Gene Bank Accession } \\
\hline & & ITS & $\mathbf{L S U}$ & SSU & $\beta$-tubulin \\
\hline Calosphaeria africana & CBS 120870 & EU367444 & EU367454 & EU367460 & EU367464 \\
\hline Calosphaeria africana & STE-U 6181 & EU367445 & EU367445 & EU367461 & EU367465 \\
\hline Calosphaeria pulchella & CBS 115999 & EU367451 & AY761075 & AY761071 & KT716476 \\
\hline Calosphaeria pulchella & CCTU 316 & JX876610 & JX876611 & - & - \\
\hline Calosphaeria pulchella & LM 06 & HM237298 & - & - & - \\
\hline Calosphaeria pulchella & SS 07 & HM237297 & - & - & - \\
\hline Calosphaeria pulchella & DC 04 & HM237299 & - & - & - \\
\hline Calosphaeria pulchella & SM 05 & HM237300 & - & - & - \\
\hline Flabellascus tenuirostris & CBS 138680 & KT716466 & KT716457 & - & KT716488 \\
\hline Flabellascus tenuirostris & CBS 138690 & KT716467 & KT716458 & - & KT716489 \\
\hline Flabellascus tenuirostris & CBS 138692 & KT716468 & KT716459 & - & KT716483 \\
\hline Flabellascus tenuirostris & CBS 139026 & KT716469 & KT716460 & - & KT716484 \\
\hline Jattaea algeriensis & CBS 120871 & EU367446 & EU367456 & EU367462 & EU367466 \\
\hline Jattaea algeriensis & STE-U 6400 & EU367448 & - & - & - \\
\hline Jattaea algeriensis & STE-U 6399 & EU367447 & EU367457 & - & - \\
\hline Jattaea aphanospora & PRM 934328 & HQ878588 & HQ878594 & - & KT716477 \\
\hline Jattaea aurea & CBS 140209 & KT716462 & KT716453 & KT716447 & KT716478 \\
\hline Jattaea bruguierae & MFLUCC 15-1277 & MG593190 & MG593189 & MG593191 & MG593192 \\
\hline Jattaea discreta & CBS 127681 & HQ878587 & HQ878593 & HQ878597 & KT716479 \\
\hline Jattaea leucospermi & CBS 119343 & EU552127 & EU552127 & - & - \\
\hline Jattaea mookgoponga & CBS 120867 & HQ878589 & EU367458 & EU367463 & EU367467 \\
\hline Jattaea mookgoponga & STE-U 6401 & EU367450 & EU367459 & - & - \\
\hline Jattaea mucronata & MFLU 16-0534 & KY034452 & KY034451 & MG593193 & - \\
\hline Jattaea ribicola & CBS 139779 & KT716463 & KT716454 & KT716448 & KT716480 \\
\hline
\end{tabular}


Table 2 Continued.

\begin{tabular}{|c|c|c|c|c|c|}
\hline \multirow[t]{2}{*}{ Taxon } & \multirow[t]{2}{*}{ Source } & \multicolumn{4}{|c|}{ Gene Bank Accession } \\
\hline & & ITS & $\mathbf{L S U}$ & SSU & $\beta$-tubulin \\
\hline Jattaea sp. 1 & HNDC 06 & GU361954 & - & - & - \\
\hline Jattaea sp. 2 & YNDC 23 & GU361945 & - & - & - \\
\hline Jattaea sp. 2 & YNDC 19 & GU361941 & - & - & - \\
\hline Jattaea sp. 3 & CBS 122684 & EU552160 & EU552160 & - & EU552167 \\
\hline Jattaea sp. 3 & CMW 22119 & EU552159 & EU552159 & - & - \\
\hline Jattaea sp. 4 & CBS 122685 & EU552161 & EU552161 & - & EU552168 \\
\hline Jattaea taediosa & PRM 934412 & KT716464 & KT716455 & KT716449 & KT716481 \\
\hline Jattaea tumidula & CBS 140208 & KT716465 & KT716456 & KT716450 & KT716482 \\
\hline Phaeoacremonium minimum & CBS 246.91 & NR077126 & - & - & AF246811 \\
\hline Phaeoacremonium novae-zealandiae & CBS 110156 & NR136064 & - & - & DQ173110 \\
\hline Pleurostoma ochraceum & CBS 131321 & JX073270 & JX073274 & JX073269 & JX073271 \\
\hline Pleurostoma ootheca & CBS 115329 & HQ878590 & AY761079 & AY761074 & JX073272 \\
\hline Pleurostoma repens & CBS 294.39 & - & AY729813 & - & JX073273 \\
\hline Pleurostoma richardsiae & CBS 270.33 & NR135933 & - & AY729812 & AY579334 \\
\hline Togniniella acerosa & CBS113726 & NR135947 & - & - & - \\
\hline Togniniella acerosa & CBS113648 & EU367453 & - & - & KT716486 \\
\hline Togniniella acerosa & CBS125298 & KT716470 & KT716461 & KT716451 & KT716485 \\
\hline
\end{tabular}




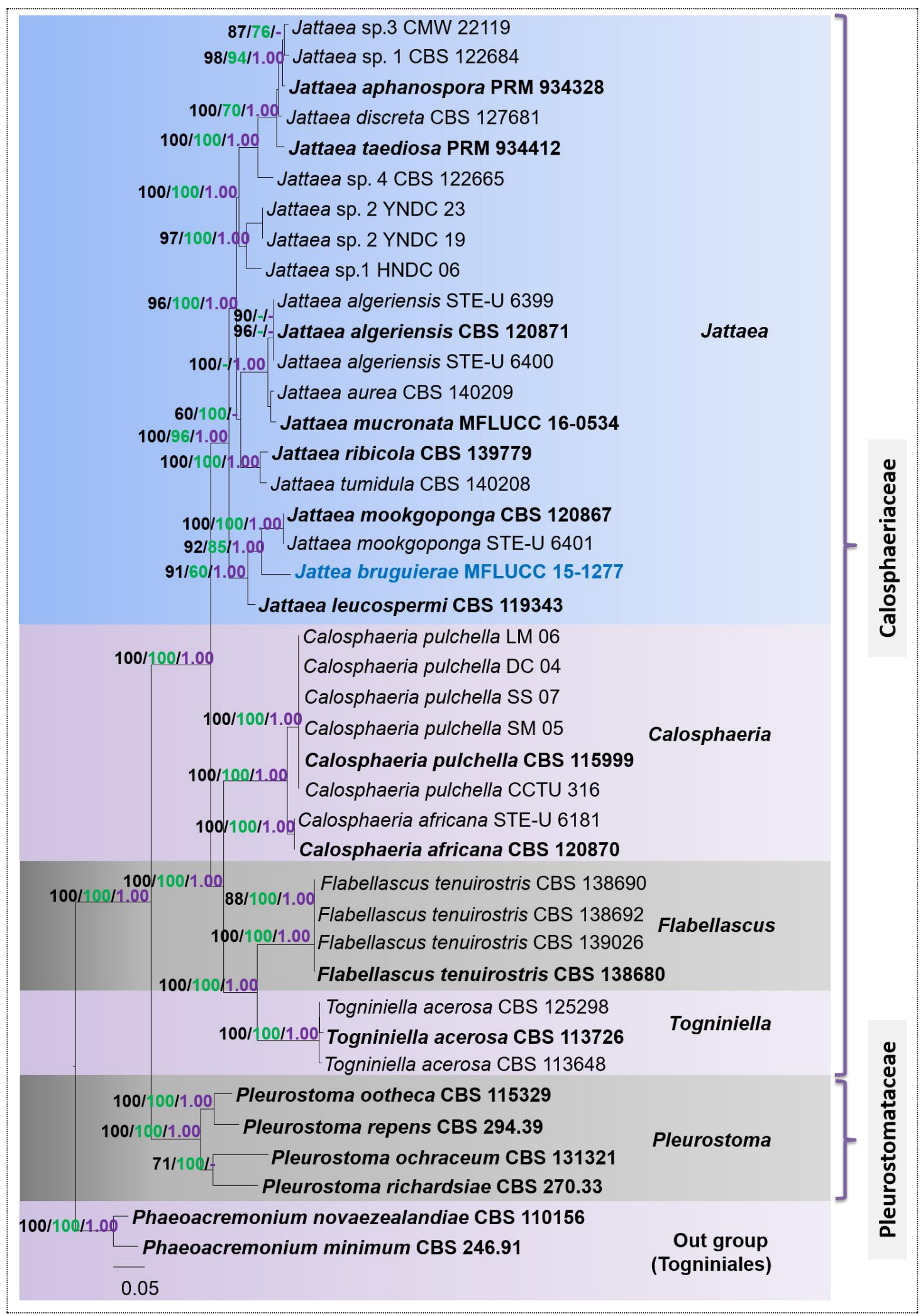

Fig. 1 - RAxML tree based on analysis of a combined dataset of ITS, LSU, SSU and $\beta$-tubulin sequence data. The scale bar indicates 0.05 changes. ML, MP bootstrap support values $>60 \%$ from 1000 replicates and BYPP > 0.95 from 5 million generations in Markov chains are shown at the nodes. Taxonomic novelty in blue and ex-type strains are in bold text. GenBank accession numbers are indicated at the end of the species name. The tree was rooted to Phaeoacremonium novaezealandiae and $P h$. minimum (Togniniaceae). 
likelihood value of -14937.759370 . Resulting trees were visualized with TreeView v. 1.6.6 (Page 1996).Maximum likelihood bootstrap values (ML) $\geq 60 \%$, Bayesian posterior probabilities (PP) $\geq$ $0.90 \%$ ) and Maximum parsimony bootstrap values (MP) $\geq 60 \%$ are given above the nodes (Fig. 1). Sequences generated in this study were deposited in GenBank and the final alignments and the trees obtained were deposited in TreeBASE (Reviewer access URL: http://purl.org/phylo/treebase/phylows/study/TB2:S21945? $\mathrm{x}$-accesscode $=\mathrm{df} 2103 \mathrm{af} 4 \mathrm{~d} 865 \mathrm{~cd} 80$ 0e7a942930166e6\&format=html) and are available under study accession no. S21945.

\section{Results}

Thirty-two taxa were included in the combined ITS, LSU, SSU and $\beta$-tubulin data set with Phaeoacremonium novaezealandiae and Ph. minimum as the out-group taxa. Parsimony analysis indicated that alignment comprised 3116 characters (including gaps) and 2354 characters were constant; 94 variable characters were parsimony-uninformative; and 668characters were parsimony informative. The most parsimonious tree out of 8 trees showed $\mathrm{TL}=2219, \mathrm{CI}=0.574, \mathrm{RI}=0.798$, $\mathrm{RC}=0.458, \mathrm{HI}=0.426$ values. Tree topology of the maximum parsimony, Bayesian analysis (not shown) was almost compatible with the ML tree and the best scoring RAxML tree, with a final likelihood value of -14937.759370 is presented in Fig 1. The novel taxon Jattaea bruguierae, grouped as a separate lineage with high bootstrap support and high posterior probability (92\% ML/ $85 \%$ MP, 1.00 PP) within Calosphaeriaceae in a clade comprising Jattaea leucospermi and Jattaea mookgoponga. However, Jattaea leucospermi and J. mookgoponga group in a monophyletic subclade with the strain of J. bruguierae (100\% ML/ 96\% MP/ $1.00 \mathrm{PP}$ ) among other Jattaea species.

\section{Taxonomy}

Jattaea bruguierae Dayarathne, Jones E.B.G. \& K.D. Hyde, sp. nov.

Fig. 2 Index Fungorum number: IF554045; Facesoffungi number: FoF03892

Etymology - Name reflects the host genus Bruguiera

Holotype - MFLU 17-2648

Saprobic on fallen decaying twigs of Bruguiera cylindrica. Sexual morph: Undetermined. Asexual morph: Mycelium composed of vegetative hyphae, on half-strength seawater MEA, hyaline, 2.5-3.5 $\mu \mathrm{m}$ wide, septate, branched, smooth, partly compacted to form hyphal strands. Conidiophores hyaline, simple or branched, elongated, erect or flexuous, up to $45 \mu \mathrm{m}$ long, sometimes ending with sterile cells. Conidiogenous cells enteroblastic, phialidic with periclinical wall thickening, discrete or adelophialides, with discrete phialides subcylindrical to elongateampulliform and constricted base, single or in conidiophores,10-40 $\times 1-3 \mu \mathrm{m}$; adelophialides cylindrical, $2.5-8 \times 1.5-3 \mu \mathrm{m}$; collarettes distinct,1-2.5 $\mu \mathrm{m}$ long, $1.5-2 \mu \mathrm{m}$ wide, with $1.5 \mu \mathrm{m}$ wide opening. Conidia 3.5-4.5 $\times 2.0-3.0 \mu \mathrm{m}(\bar{x}=4 \times 2.5 \mu \mathrm{m}, \mathrm{n}=20)$, hyaline, aseptate, cylindrical with a tapered and truncate base, smooth-walled, sometimes held together in droplets.

Cultural characteristics - Colonies on half-strength seawater MEA flat, fimbriate edge,with floccose aerial mycelium; surface white, buff, cinnamon to orange, turning sepia with age, reverse pale luteous, orange, turning amber with age, $30 \mathrm{~mm}$ within 2 weeks $\left(25^{\circ} \mathrm{C}\right)$. Conditions for growth: min $15{ }^{\circ} \mathrm{C}$, max $30{ }^{\circ} \mathrm{C}$, opt $25{ }^{\circ} \mathrm{C}$. Colonies on half-strength seawater PDA flat, fimbriate edge, with floccose aerial mycelium; surface white, buff, cinnamon, turning dark sepia with age, reverse pale luteous, orange, turning umber with age. $20 \mathrm{~mm}$ within 2 weeks $\left(25^{\circ} \mathrm{C}\right)$

Material examined - THAILAND, Ranong Province, Amphoe Maung, Mu 4 Tombol Ngao, Ranong Mangrove Research Center (GPS: $9^{\circ} 43^{\prime}$ to $9^{\circ} 57^{\prime} \mathrm{N}$; $98^{\circ} 29^{\prime}$ to $98^{\circ} 39^{\prime} \mathrm{E}$ ), on fallen decaying twig of Bruguiera cylindrica, 6 December 2016, Monika C. Datarathne, MCD 038 (MFLU 172648 holotype), ex-type living culture, MFLUCC 15-1277, TBRC.

Notes - Jattaea bruguierae which is currently known only from its asexual morph, is distinct from J. mookgoponga by its hyaline, elongated conidiophores and cylindrical conidia with a tapered base, while J. mookgoponga comprises yellow brown conidiophores and cylindrical to 
ellipsoidal conidia with obtuse ends on MEA (Damm et al. 2008). Based on phylogenetic analysis, J. leucospermi is also closely related to Jattaea bruguierae which is so far known only as a phialophora-like asexual morph.

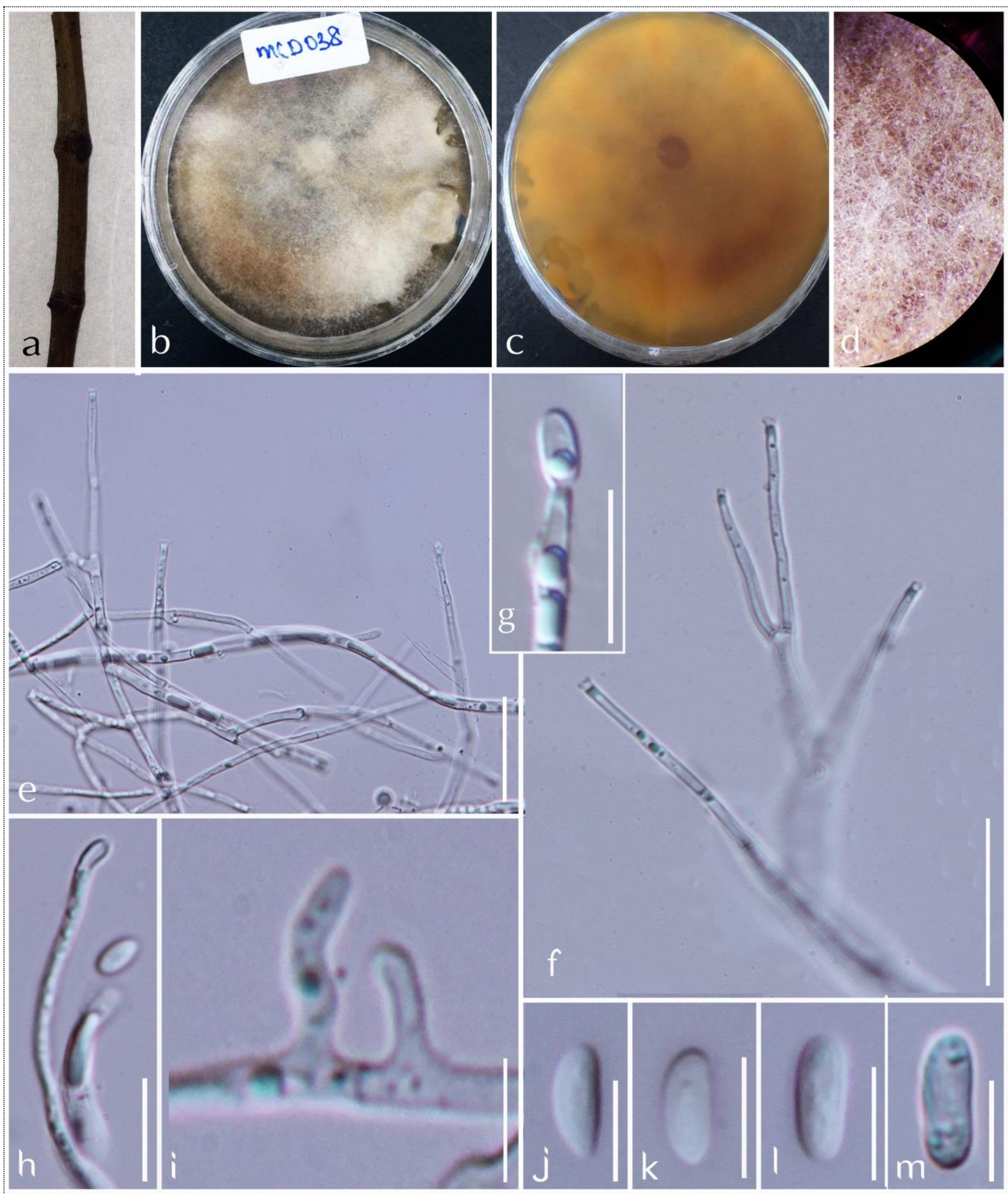

Fig. 2 - Jattaea bruguierae (MFLU 17-2648, holotype). a Host. b, c Culture on half strength sea water MEA (b from upper, c from lower). $d$ Appearance of type in culture. e Conidiophores. $f-i$ Phialides. $\mathrm{j}-\mathrm{m}$ Conidia. Scale bars: $\mathrm{e}, \mathrm{f}=20 \mu \mathrm{m}, \mathrm{g}-\mathrm{i}=10 \mu \mathrm{m}, \mathrm{j}-\mathrm{m}=5 \mu \mathrm{m}$. 


\section{Discussion}

The present study introduces a new species in the genus Jattaea (Jattaea bruguierae), provided with a morphological description, illustrations and combined analyses of LSU, SSU, ITS and $\beta$-tubulin sequence data. Recently, Réblová et al. (2015) has used combined LSU, SSU, ITS, RPB2 and $\beta$-tubulin genes in their phylogenetic reconstruction of Calosphaeriales. Unfortunately, we did not obtain RPB2 sequence data even after several attempts with different PCR temperature profiles by using the primers fRPB2-5F and fRPB2-7cR. However, the concatenated dataset of LSU, SSU, ITS and $\beta$-tubulin sequences reveals a phylogeny which is topologically congruent to Réblová et al. (2015). Hence, we are confident with our taxonomic arrangement of the novel taxon which is phylogenetically close to Jattaea leucospermi and J. mookgoponga with strong bootstrap support (100\% ML/ 96\% MP/ 1.00 PP, Fig. 1). Our species is morphologically different from all the other previously described species in having hyaline, elongated conidiophores and cylindrical conidia with a tapered base, while others have yellow brown conidiophores and cylindrical to ellipsoidal conidia with obtuse ends. Therefore, both morphological and phylogenetic support ensures that our species definition and justification for establishing a new species is scientifically valid within Calosphaeriaceae. Jattaea was recently revisited with 17 accepted species and asexual morphs linked to the genus comprise reduced, morphologically similar dematiaceous hyphomycetes with phialidic conidiogenous cells similar to Phialophora (Réblová et al. 2015). The asexual morphs of Jattaea have been experimentally established for nine of the 17 accepted species, i.e. J. algeriensis Berl., J. aphanospora Réblová \& J. Fourn., J. aurea Réblová \& J. Fourn., J. discrete (Berl.) Réblová, J. leucospermi Marinc., M.J. Wingf. \& Crous, J. mookgoponga Damm \& Crous, J. ribicola Réblová \& Jaklitsch, J. taediosa (Sacc.) Réblová \& Jaklitsch and J. tumidula (Sacc.) Réblová, by the previous studies of Damm et al. (2008), Réblová (2011) and Réblová et al. (2015). Jattaea mookgoponga and our novel species, J. bruguierae are known only as asexual morphs, while all the other asexual morphs have been linked with their sexual morphs (Réblová et al. 2015). Although the differences between asexual morphs of Jattaea based on their morphology they are distinctly different at the molecular phylogenetic level (Réblová 2011, Réblová et al. 2015) and as demonstrated in our study. Different authors have described colony characteristics of asexual morphs of Jattaea species in different culture media, such as normal PDA, MEA, potatocarrot agar (PCA, Gams et al. 1998), synthetic nutrient-poor agar medium (SNA, Nirenberg 1976). In our study, we described cultural characteristics of J. bruguierae on half-strength seawater PDA and half-strength seawater MEA media and it grew fast and sporulated well. However, we did not observe conidial structures on the host surface. Therefore, we designated a dry culture along with the herbarium material as the holotype. Our species also morphologically resembles asexual morphs of Phaeoacremonium spp. However, according to phylogenetic analysis it is confirmed that our novel species does not belong to Phaeoacremonium. Jattaea mucronata, introduced by AbdelWahab et al. (2017), is the first documentation of a sexual morph of Jattaea associated with a marine habitat while $J$ bruguierae is the first record of an asexual morph from mangroves.

\section{Acknowledgements}

We are grateful to the Thailand Research Fund (TRF) grant no RSA5980068 entitled Biodiversity, phylogeny and role of fungal endophytes on above parts of Rhizophora apiculata and Nypa fruticans; National Research Council of Thailand (NRCT) for a grant entitled Diseases of mangrove trees and maintenance of good forestry practice (Grant number: 60201000201) and Thailand Research Fund (TRF) grant no MRG6080089. Pranami Abeywickrama offers her sincere gratitude to Dr. Ji Ye Yan for providing laboratory facilities for the molecular work. Dr. Shaun Pennycook is acknowledged for the help in Latin diagnosis for the fungal name. Monika Dayarathne offers her deepest gratitude to Dhanushka Wanasinghe and Sajeewa Maharachchikumbura for their helpful comments and advice. 


\section{References}

Abdel-Wahab M, Dayarathne M, Suetrong S, Guo SY et al. 2017 - New saprobic marine fungi and a new combination. Botanica Marina 60, 469-488.

Atlas RM. 2006 - The handbook of microbiological media for the examination of food. CRC Press $314 \mathrm{pp}$.

Berlese AN. 1900 - Icones Fungorum omnium hucusque cognitorum 3, 1894-1905.

Chomnunti P, Hongsanan S, Aguirre-Hudson B, Tian Q et al. 2014 - The sooty moulds. Fungal Diversity $66,1-36$.

Clements FE, Shear CL. 1931 - The genera of fungi. H.W. Wilson Co., New York

Damm U, Crous PW, Fourie PH. 2008 - A fissitunicate ascus mechanism in the Calosphaeriaceae, and novel species of Jattaea and Calosphaeria on Prunus wood. Persoonia 20, 39-52.

Gams W, Hoekstra ES, Aptroot A. 1998 - CBS course of mycology, 4th edn. Baarn, The Netherlands: Centraalbureau voor Schimmelcultures

Glass NL, Donaldson GC. 1995 - Development of primer sets designed for use with the PCR to amplify conserved genes from filamentous ascomycetes. Applied and Environmental Microbiology 61, 1323-1330

Hall TA. 1999 - BioEdit: a user-friendly biological sequence alignment editor and analysisprogram for Windows 95/98/NT. Nucleic Acids Symposium Series 41, 95-98.

Huelsenbeck JP, Ronquist FR. 2001 - MrBayes: Bayesian inference of 380 phylogenetics trees. Biometrics 17, 754-755.

Index Fungorum 2017 - http://www.indexfungorum.org/Names/Names.asp. (Accessed: August 2017).

Jayasiri SC, Hyde KD, Ariyawansa HA, Bhat J. et al. 2015 - The Faces of Fungi database: fungal names linked with morphology, phylogeny and human impacts. Fungal Diversity 74, 3-18.

Kishino H, Hasegawa M. 1989 - Evaluation of the maximum likelihood estimate of the evolutionary tree topologies from DNA sequence data. Journal of Molecular Evolution 29, $170-179$.

Nirenberg HI. 1976 - Untersuchungen über die morphologische und biologische Differenzierung in der Fusarium-Sektion Liseola. Mitteilungen aus der Biologischen Bundesanstalt für Landund Forstwirtschaft Berlin-Dahlem 169, 1-117.

Nylander JAA. 2004 - MrModeltest 2.2: Program distributed by the author. Evolutionary Biology Centre, Uppsala University, Sweden.

Rannala B, Huelsenbeck JP, Yang Z, Nielsen R. 1998 - Taxon sampling and the accuracy of large phylogenies. Systematic Biology 47(4), 702-710.

Réblová M, Jaklitsch WM, Réblová K, Štěpánek V. 2015 - Phylogenetic reconstruction of the Calosphaeriales and Togniniales using five genes and predicted RNA secondary structures of ITS, and Flabellascus tenuirostris gen. et sp. nov. Plos One 10(12), e0144616.

Réblová M. 2011 - New insights into the systematics and phylogeny of the genus Jattaea and similar fungi of the Calosphaeriales. Fungal Diversity 49, 167-198.

Rehner SA, Samuels GJ. 1994 - Taxonomy and phylogeny of Gliocladium analysed from nuclear large subunit ribosomal DNA sequences. Mycological Research 98, 625-634.

Ronquist F, Huelsenbeck JP. 2003 - MrBayes 3: Bayesian phylogenetic inference under mixed models. Bioinformatics 19(12), 1572-1574.

Ronquist F, Teslenko M, van der Mark P. 2012 - MrBayes 3.2: efficient Bayesian phylogenetic inference and model choice across a large model space. Systematic Biology 61, 539-542.

Silvestro D, Michalak I. 2012 - RaxmlGUI: a graphical front-end for RAxML. Organisms Diversity \& Evolution 12: 335-337.

Stamatakis A. 2014 - RAxML version 8: a tool for phylogenetic analysis and post-analysis of large phylogenies. Bioinformatics 30(9), 1312-1313. 
Tamura K, Peterson D, Peterson N, Stecher G et al. 2011 - MEGA5: molecular evolutionary genetics analysis using maximum likelihood, evolutionary distance and maximum parsimony methods. Molecular Biology and Evolution 28: 2731-2739.

Vilgalys R, Hester M. 1990 - Rapid genetic identification and mapping of enzymatically amplified ribosomal DNA from several Cryptococcus species. Journal of Bacteriology 172, 4238-4246.

White T, Bruns T, Lee S, Taylor J. 1990 - Amplification and direct sequencing of fungal ribosomal RNA genes for phylogenetics. PCR protocols a guide to methods and applications 18, 315322.

Zhaxybayeva O, Gogarten JP. 2002 - Bootstrap, Bayesian probability and maximum likelihood mapping: exploring new tools for comparative genome analyses. BMC genomics 3, 1-4. 